\title{
Erratum to "Routine Episiotomy Practice at a Tertiary Care Center in Saudi Arabia" [Open Journal of Obstetrics and Gynecology 6 (2016) 794-797]
}

\begin{abstract}
Ayman Oraif
Department of Obstetrics \& Gynecology, Faculty of Medicine, King Abdulaziz University, Jeddah, Saudi Arabia Email: ayman_oraif@yahoo.com
\end{abstract}

Received: September 11, 2017

Accepted: December 3, 2017

Published: December 6, 2017

Copyright (C) 2018 by authors and Scientific Research Publishing Inc. This work is licensed under the Creative Commons Attribution International License (CC BY 4.0).

http://creativecommons.org/licenses/by/4.0/
The original online version of this article (Oraif, A. (2016) Routine Episiotomy Practice at a Tertiary Care Center in Saudi Arabia. Open Journal of Obstetrics and Gynecology, 6, 794-797.

http://dx.doi.org/10.4236/ojog.2016.613097) was published without the coauthors mistakenly. To reflect the contribution and responsibility of the coauthors at the time of the study, we revised authorship and affiliation of the article. The author wishes to correct the errors to:

\section{(c) (i) Open Access}

\section{Ayman Oraif*, Ammar Alfattni, Abdulhadi Alama, Abdulrahman Hawari, Yazeed Al Subhi, Hisham Alghanmi \\ Department of Obstetrics \& Gynecology, King Abdulaziz University, Jeddah, Saudi Arabia \\ Email: ^ayman_oraif@yahoo.com}

